\title{
28. Understanding water scarcity: Definitions and measurements
}

\author{
Chris White \\ URS, United Kingdom
}

\begin{abstract}
Water scarcity, which can broadly be understood as the lack of access to adequate quantities of water for human and environmental uses, is increasingly being recognised in many countries as a serious and growing concern. As a result, the term 'water scarcity' is regularly used by the media, government reports, nongovernmental organisations (NGOs), international organisations such as the United Nations (UN) and Organisation for Economic Co-operation and Development (OECD), as well as in the academic literature, to highlight areas where water resources are under pressure.
\end{abstract}

Despite its frequent use, however, there is no consensus on how water scarcity should be defined or how it should be measured. Thus, a reference to water scarcity in one report may measure something different to other reports that use the same term. This can create confusion as to what water scarcity means and lead to different answers to the question of which regions are under the most water stress.

In order to reduce this confusion, this chapter looks at some of the most commonly used methods of defining and measuring water scarcity, so that readers can understand what is meant in each case.

One of the most commonly used measures of water scarcity is the 'Falkenmark indicator' or 'water stress index'. This method defines water scarcity in terms of the total water resources that are available to the population of a region; measuring scarcity as the amount of renewable freshwater that is available for each person each year. If the amount of renewable water in a country is below 1700 cubic metres $\left(\mathrm{m}^{3}\right)$ per person per year, that country is said to be experiencing water stress; below $1000 \mathrm{~m}^{3}$ it is said to be experiencing water scarcity; and below $500 \mathrm{~m}^{3}$, absolute water scarcity (Falkenmark et al. 1989).

The water stress index method is commonly used because it is straightforward, easy to use, and the data needed is readily available. Such a simplistic approach does, however, have limitations:

1. It ignores important regional differences in water availability, only measuring water scarcity at a country level. 
2. It fails to account for whether or not those water resources are accessible, for example, some of the freshwater resources of a country may be stored deep underground or may be heavily polluted.

3. It does not include man-made sources of freshwater, such as desalination plants, which increase water availability beyond what is naturally available.

4. It does not account for the fact that different countries, and regions within countries, use different amounts of water. In Australia for example, most of the demand for water is focused around the major urban and agricultural centres such as in the Murray-Darling Basin, with much less used in the sparsely populated centre (Rijsberman 2006).

An alternative way of defining and measuring water scarcity is to use a criticality ratio. This approach relaxes the assumption that all countries use the same amount of water, instead defining water scarcity in terms of each country's water demand compared to the amount of water available; measuring scarcity as the proportion of total annual water withdrawals relative to total available water resources (Raskin et al. 1997). Using this approach, a country is said to be water scarce if annual withdrawals are between 20-40 per cent of annual supply, and severely water scarce if they exceed 40 per cent.

While this approach avoids the simplistic assumption that all countries have the same demand for water, it also has its limitations:

1. It does not consider man-made increases in water supply (such as desalination).

2. It ignores water withdrawals that are recycled and reused.

3. It doesn't consider the capacity of countries to adapt to lower water availability through changing behaviour or new technology (Rijsberman 2006).

A third measure of water scarcity was developed by the International Water Management Institute (IWMI). This approach attempts to solve the problems listed above by including: water infrastructure, such as water in desalination plants, into the measure of water availability; recycled water, by limiting measurements of water demand to consumptive use rather than total withdrawals; and, the adaptive capacity of a country by assessing its potential for infrastructure development and efficiency improvements (Seckler et al. 1998).

Using this approach, the IWMI classifies countries that are predicted to be unable to meet their future water demand, without investment in water infrastructure and efficiency, as economically water scarce; and countries predicted to be unable to meet their future demand, even with such investment, as physically water scarce (Molden et al. 2007). 
While the IWMI measure of water scarcity is more sophisticated, its complexity means that it requires significant amounts of time and resources to estimate. This approach also fails to consider the ability of people within countries to adapt to reduced water availability by importing food grown in other countries, or by using water saving devices. The ability to adapt also depends on the economic resources available in countries as a whole, as well as to individuals within a country. For instance, wealthy residents in rich countries are more likely to be able to adapt to reduced water availability than poor people in developing countries.

A fourth approach to measuring water scarcity is the 'water poverty index'. This approach attempts to take into account the role of income and wealth in determining water scarcity by measuring: (1) the level of access to water; (2) water quantity, quality, and variability; (3) water used for domestic, food and productive purposes; (4) capacity for water management; and, (5) environmental aspects (Sullivan et al. 2003). The complexity of this approach, however, means that it is more suited for analysis at a local scale, where data is more readily available, than on a national level.

There is, therefore, no single definition of water scarcity; different measurements capture different aspects of the pressures on water resources, and there isn't one measure that captures them all. This point is illustrated in Figure 1, which shows two different measures of water scarcity for Africa and Western Europe; one which accounts for the impact that access to water technology can have on water scarcity, and one which does not.

First, by using a criticality ratio, the authors estimate the level of water scarcity based on a number of stressors (labelled in Figure 1 as Incident HWS threat). Since this measure does not include the impact that investment in technological development can have on improving water security, they then estimate an 'investment benefits factor', which measures the investment capabilities of each country. This includes the investment benefits factor with the measure of water scarcity to estimate an adjusted measure of water scarcity when technological capacity is taken into account (labelled as Adjusted HWS threat) (Vorosmarty et al 2010). 

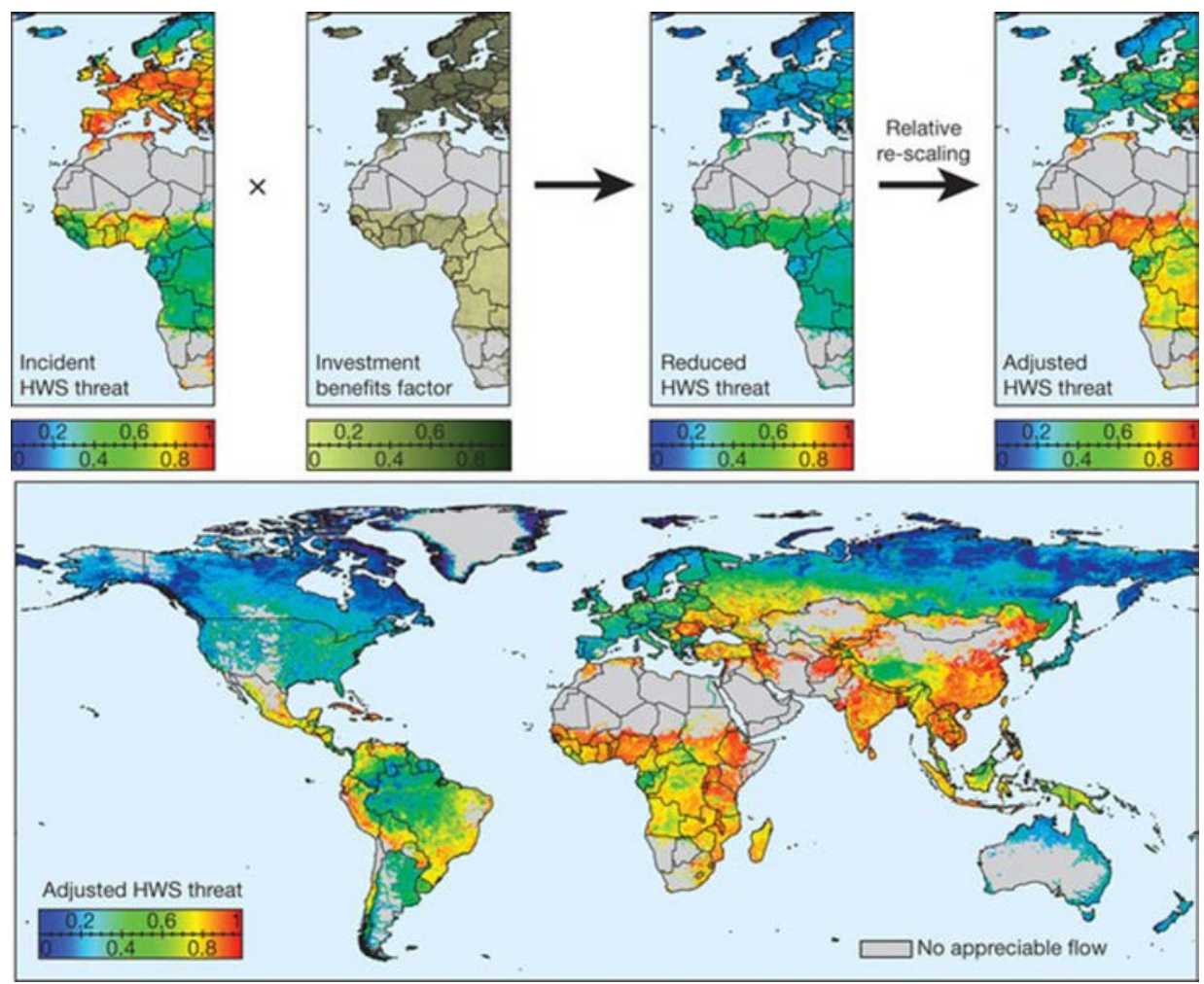

Figure 1: Different measures of water scarcity can produce different answers to the question of which regions are under the most water stress

Source: Vorosmarty et al. 2010.

As Figure 1 shows, the way in which water scarcity is defined and measured has direct, and sometimes contradictory, implications on how serious the issue is perceived to be in different regions. As a result, relying on a single indicator may give a misleading impression about water scarcity issues. It is therefore important when discussing 'water scarcity', to be clear how the term is defined and which aspects of water scarcity it measures and to recognise that one measure by itself is not enough to give the whole picture.

Chris White is an Environmental Economist at URS, London, where his main area is working with the public and private sector on valuing the services provided by the environment in order to improve decision-making and account for impacts on natural capital. White is also a Research Associate at the Centre for Water Economics, Environment and Policy, The Australian National University and Managing Editor of the Global Water Forum. 


\section{References}

Falkenmark, M., Lundquist, J. and Widstrand, C., 1989. 'Macro-scale water scarcity requires micro-scale approaches: aspects of vulnerability in semiarid development', Natural Resources Forum, 13(4):258-67.

Molden, D. (ed.), 2007. Water for Food, Water for Life: A comprehensive assessment of water management in agriculture, Earthscan/International Water Management Institute, London.

Raskin, P., Gleick, P.H., Kirshen, P., Pontius, R.G., and Strzepek, K., 1997. Water Futures: Assessment of long-range patterns and prospects, Stockholm Environment Institute.

Rijsberman, F.R., 2006. 'Water scarcity: fact or fiction?', Agricultural Water Management, 80:5-22.

Seckler, D., Amarasinghe, U., Molden, D., de Silva, R. and Barker, R., 1998. 'World water demand and supply, 1990 to 2025: scenarios and issues', International Water Management Institute (IWMI) Research Report 19, IWMI, Colombo.

Sullivan, C.A., et al., 2003. 'The water poverty index: development and application at the community scale', Natural Resources Forum, 27:189-99.

Vorosmarty, C.J., et al., 2010. 'Global threats to human water security and river biodiversity', Nature, 467:555-61. 
This text taken from Global Water: Issues and Insights by R. Quentin Grafton, Paul Wyrwoll, Chris White and David Allendes, published May 2014 by ANU Press, The Australian National University, Canberra, Australia. 